\title{
Animal Models of Cardiovascular Diseases
}

\author{
Carlos Zaragoza, ${ }^{1}$ Carmen Gomez-Guerrero, ${ }^{2}$ Jose Luis Martin-Ventura, ${ }^{2}$ \\ Luis Blanco-Colio, ${ }^{2}$ Begoña Lavin, ${ }^{1}$ Beñat Mallavia, ${ }^{2}$ Carlos Tarin, ${ }^{2}$ Sebastian Mas, ${ }^{2}$ \\ Alberto Ortiz, ${ }^{2}$ and Jesus Egido ${ }^{2}$ \\ ${ }^{1}$ Department of Epidemiology, Atherothrombosis and Cardiovascular Imaging, Fundacion Centro Nacional Investigaciones \\ Cardiovasculares Carlos III (CNIC), Sinesio Delgado 3, 28029 Madrid, Spain \\ ${ }^{2}$ Renal and Vascular Research Laboratory, IIS-Fundacion Jimenez Diaz, Universidad Autonoma, Avda Reyes Catolicos 2, \\ 28040 Madrid, Spain \\ Correspondence should be addressed to Jesus Egido, jegido@fjd.es
}

Received 11 October 2010; Revised 4 January 2011; Accepted 17 January 2011

Academic Editor: Oreste Gualillo

Copyright ( $) 2011$ Carlos Zaragoza et al. This is an open access article distributed under the Creative Commons Attribution License, which permits unrestricted use, distribution, and reproduction in any medium, provided the original work is properly cited.

\begin{abstract}
Cardiovascular diseases are the first leading cause of death and morbidity in developed countries. The use of animal models have contributed to increase our knowledge, providing new approaches focused to improve the diagnostic and the treatment of these pathologies. Several models have been developed to address cardiovascular complications, including atherothrombotic and cardiac diseases, and the same pathology have been successfully recreated in different species, including small and big animal models of disease. However, genetic and environmental factors play a significant role in cardiovascular pathophysiology, making difficult to match a particular disease, with a single experimental model. Therefore, no exclusive method perfectly recreates the human complication, and depending on the model, additional considerations of cost, infrastructure, and the requirement for specialized personnel, should also have in mind. Considering all these facts, and depending on the budgets available, models should be selected that best reproduce the disease being investigated. Here we will describe models of atherothrombotic diseases, including expanding and occlusive animal models, as well as models of heart failure. Given the wide range of models available, today it is possible to devise the best strategy, which may help us to find more efficient and reliable solutions against human cardiovascular diseases.
\end{abstract}

\section{Introduction}

Cardiovascular diseases are the first leading cause of death and morbidity in developed countries. Cardiac and vascular complications are complex multifactorial pathologies, in which both genetic and environmental factors are implicated, thus making them very difficult to prevent. The development of animal models of cardiovascular disease (CVD), including cardiac and atherothrombotic diseases, has provided us today with important insights into the pathophysiology, and they were found to be essential tools to evaluate new therapeutic strategies to predict and to prevent these complications.

Here, we will summarize the most common models of cardiovascular diseases, including those implemented in both large and small animals, designed for helping to cover with more precision and to better understand every single aspect related to these human pathologies. In particular, we will describe models of atherothrombotic diseases, including expanding abdominal aortic aneurysms (AAA), thoracic aneurysms, and occlusive atherosclerotic diseases, as well as models of heart failure. These situations constitute today a significant challenge since predictors to evaluate early detection and forecast progression are crucial in these pathologies, yet they are poorly explored.

\section{Animal Models of Atherothrombotic Disease}

2.1. Mouse Models. Atherosclerosis is a complex multifactorial disease with different etiologies that synergistically promote lesion development. Mouse models have proved to be useful to study development and progression of atherosclerotic lesion, and several reviews have extensively discussed the different available models [1-3]. In particular, 
knockout and transgenic mouse models for atherosclerosis have been instrumental in understanding the molecular and cellular mechanisms involved in atherogenesis, and in evaluating the effectiveness of new and existing atherosclerotic drugs [4].

As wild-type mice are resistant to lesion development, the current mouse models for atherosclerosis are based on genetic modifications of lipoprotein metabolism with additional dietary changes. Among them, low-density lipoprotein receptor-deficient mice (LDLR-/- mice) and apolipoprotein E-deficient mice (apoE-/- mice) are the most widely used. Atherosclerotic lesions seen in these models can be exacerbated by the addition of risk factors such as hypertension or diabetes. Mice have become widely used as models of human atherosclerosis as they offer advantage compared with other species (Table 1).

2.2. LDLR-/- Mice. The LDLR-/- mouse represents a model of familial hypercholesterolemia due to one of the mutations affecting the LDLR, and the plasma lipoprotein profile resembles that of humans. Mice, which are genetically deficient in LDLR manifested delayed clearance of VLDL and LDL from plasma. As a result, LDLR-/- mice exhibit a moderate increase of plasma cholesterol level and develop atherosclerosis slowly on normal chow diet $[5,6]$. Interestingly, the severity of the hypercholesterolemia and atherosclerotic lesions in LDLR-/- mice can be accelerated by feeding a high-fat, high-cholesterol diet [5-7], by mutating the apoB gene into an uneditable version $[8,9]$, and by crossing either with leptin-deficient mice [10] or with apoB100 transgenic mice [11]. Under these conditions, the lesions in the aorta can progress beyond the foam-cell fattystreak stage to the fibroproliferative intermediate stage.

In addition to LDLR-/- mice, the LDLR and apoE double-deficient mouse (LDLR-/-apoE-/-) which develops severe hyperlipidemia and atherosclerosis even on a regular chow diet, has been proposed as a suitable model to study the antiatherosclerotic effect of compounds without having to feed the animals an atherogenic diet $[12,13]$. However, the response of both LDLR-/- and LDLR-/-apoE-/- mice to the treatment with hypolipidemic drugs varies from lowering of plasma cholesterol without atherosclerosis decrease to a weak lesion reduction with or without lower plasma cholesterol $[4,14]$. By contrast, those mice effectively respond to agonists of peroxisome proliferator-activated receptor (PPAR) or liver X receptor $[15,16]$. This great variability indicates that LDLR-/is probably not well-suited for analyzing the cholesterollowering and antiatherogenic effects of drugs.

2.3. ApoE-/- Mice. In 1992 two different groups simultaneously generated the apoE- - - mice by homologous recombination in embryonic stem cells $[17,18]$. Homozygous deficiency in apoE gene results in a marked increase in the plasma levels of LDL and VLDL due to a failure in their clearance through the LDLR and LDLR-related proteins. The apoE-/- mouse contains the entire spectrum of lesions observed during atherogenesis and was the first mouse model described to develop lesions similar to those of human [17, $18]$.

Under normal dietary conditions, apoE $-/-$ mice have dramatically elevated plasma levels of cholesterol, and they develop extensive atherosclerotic lesions widely distributed throughout the aorta [18-20]. This process can be exacerbated on a high-fat diet, with female mice more susceptible than male mice [19]. A chronological analysis of atherosclerotic lesions in apoE- $-/-$ mice revealed that the sequential events involved in lesion formation in this model are strikingly similar to those in larger animal models and in humans. Predilection sites for atherosclerotic lesions in apoE-/mice are the aortic root, followed by the aortic arch, the brachiocephalic trunk, the left carotid, and subclavian and coronary arteries $[6,21]$. Aortic lesions rapidly develop from initial fatty streaks comprised primarily of foam cells with migrating smooth muscle cells to more complex lesions in middle-aged mice. These advanced lesions are heterogeneous but typically composed of a necrotic core surrounded by proliferating smooth muscle cells and extracellular matrix proteins $[20,22]$.

The apoE-/- mice are currently the most widely utilized animal model for the study of atherosclerosis. In fact, the effect of many genes on the development of atherosclerosis has been examined by crossing the apoE- $-1-$ mice with other genetically manipulated animals. Furthermore, the apoE-Imouse serves as a useful tool to: (i) identify atherosclerosissusceptibility-modifying genes, by the candidate-gene and gene-mapping methods, (ii) decipher molecular mechanism and cell types involved in atherogenesis, (iii) search into the drug effects on atherosclerosis, and (iv) assess novel therapies that prevent lesion progression. In this sense, the apoE-/- mouse model was used to test additional therapeutic effects of statins beyond those attributable solely to cholesterollowering. One of the first observations was the paradoxical effect of simvastatin on atherogenesis in both apoE-/- and LDLR-/- mice [23]. In contrast to the atheroprotective effect of simvastatin in LDLR-/mice, age-matched apoE-/- showed elevated serum total cholesterol and increased aortic plaque area, thus suggesting that the therapeutic effect of simvastatin may depend on the presence of a functional apoE [23]. In spite of this, the antiatherosclerotic effects of other statins have been effectively proven in apoE-/- mice $[24,25]$. Several other compounds, such as angiotensin II receptor antagonists or PPAR agonists [26] also reduced the extent and severity of atherosclerotic lesions without lowering plasma cholesterol in apoE- $/-$ mice. However, the recent finding of increased atherogenesis in apoE-/ - mice treated with PPAR alpha and PPAR gamma agonists is consistent with clinical findings of the adverse cardiovascular events of dual therapy [27].

Nevertheless, a major limitation of the apoE-/- mouse model is the infrequency of plaque rupture and thrombosis, two common complications of human atherosclerosis. Ischemic cardiomyopathy has been occasionally found in aged mice [20], but interestingly, rapid coronary artery occlusion, myocardial infarction, and even premature death occur when apoE- $/-$ mice were crossed with mice deficient in scavenger receptor class B type I or its adaptor protein 
TABLE 1: Animal models of atherosclerosis: advantages and limitations.

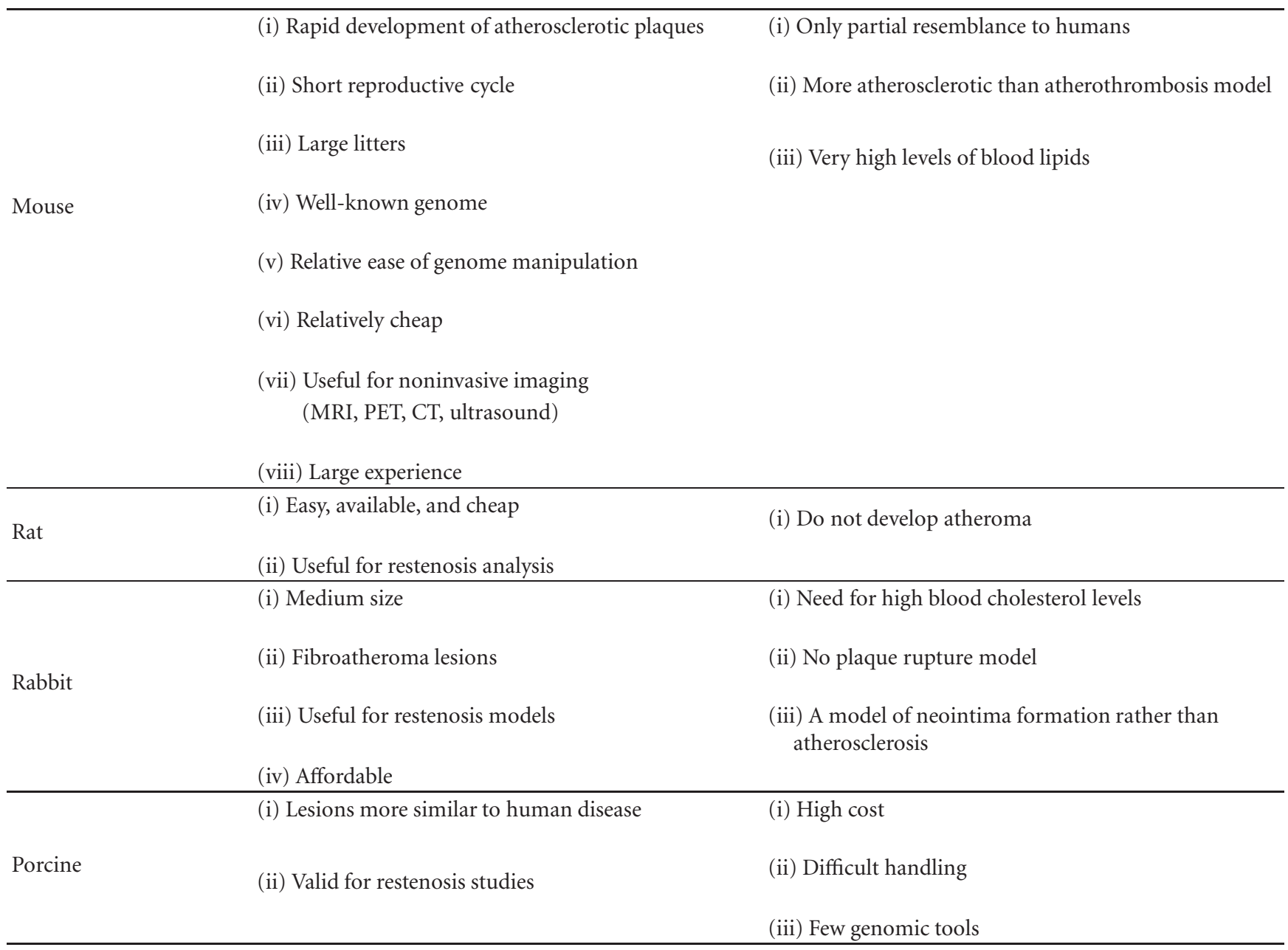

$[28,29]$, thus mimicking many cardinal features of human coronary heart disease.

2.4. Transgenic Mice. Transgenic technologies have provided a series of very useful mouse models to study hyperlipidemia and atherosclerosis. Among them, mice expressing mutant forms of apoE, such as apoE3Leiden (E3L) and apoE (Arg $112 \rightarrow$ Cys $\rightarrow 142$ ) transgenic mice, are the more widely studied. These mice display a lipoprotein profile comparable to that of patients with dysbetalipoproteinemia, in which plasma total cholesterol and triglycerides are mainly confined to (V) LDL [30]. The E3L transgenic mice develop atherosclerotic lesions with all the characteristics of human vasculopathy, varying from fatty streak to mild, moderate, and severe plaques $[30,31]$. Furthermore, E3L transgenic mice and the more recently developed $\mathrm{E} 3 \mathrm{~L} / \mathrm{Cholesteryl}$ ester transfer protein (CETP) transgenic mice have been shown to be more sensitive to a variety of hypolipidemic drugs and PPAR agonists than apoE-/- and LDLR $-/-$ mice $[4,32]$.

2.5. Mouse Models of Diabetes-Accelerated Atherosclerosis. Diabetes is a high risk factor of cardiovascular disease. The cardiovascular complications of diabetes are manifested primarily as ischemic heart disease caused by accelerated atherosclerosis, and also as cardiomyopathy. Several models are available to study atherosclerosis and cardiomyopathy associated with diabetes, including apoE-/ - and LDLR -/mice in which type 1 diabetes is induced by streptozotocin or viral injection $[33,34]$. In both mice, diabetes induction did not markedly change plasma lipid levels, thereby mimicking the accelerated atherosclerosis seen in patients with type 1 diabetes. Importantly, streptozotocin-injected atherosclerotic mice exhibited increased atherosclerosis in the aortic sinus, carotid artery, and abdominal aorta, as well as calcifications in the proximal aorta $[34,35]$.

In brief, mouse models have been very useful to unveil the importance of inflammatory and immunological mechanisms in the formation and progression of atheroma plaque. Recently, an enormous interest for the use of noninvasive magnetic resonance imaging (MRI) in mouse models of atherosclerosis has arisen [36], since MRI accurately characterizes the location, the size and the shape of lesions. In addition, MRI allows the differentiation between fibrous and lipid components of regress in plaques in mice. In combination with noninvasive imaging technologies, mouse models of atherosclerosis today also serve to test novel 
contrast agents, and to design and target specific molecules involved in high-risk plaque.

2.6. Rabbit Models. The high-cholesterol diet rabbit model has been widely used for experimental atherosclerosis. Back in 1913, cholesterol was found to cause atherosclerotic changes in the rabbit arterial intima, which is very similar to human atherosclerosis. Atherosclerotic lesions also develop in normolipemic rabbits as a result of repeated, or continuous intimal injury by an indwelling aortic polyethylene catheter, balloon angioplasty or nitrogen exposure. Therefore, many studies have used the rabbit model with highcholesterol diet, arterial wall injury, or, most commonly, a combination of these two methods. In all these models, the observed lesions resemble, at least in part, those seen in human plaques, mainly regarding the inflammatory component, though the vascular smooth muscle cell proliferation determines for a great deal the lesion.

The rabbit model has largely been used to study the influence of lipid lowering (by diet or statins) on the plaque formation and "stabilization." Those studies have contributed to unveil the mechanisms by which lipid lowering reduces macrophage accumulation and other aspects of atheroma inflammation $[37,38]$.

Recently, we have set up a novel rabbit model to examine the influence of inflammation on atherosclerotic plaque. The aim was to study some mechanisms by which atherosclerosis is particularly severe in patients with rheumatoid arthritis. Briefly, the model consists in a combination of femoral injury in hyperlipidemic rabbits and induced acute knee arthritis. Those animals had more intensive vascular lesions than animals without inflammation. This model could represent a novel approach to the study, inflammation-associated atherosclerosis [39].

A model for plaque rupture has been also developed in rabbits. Shimizu and coworkers [40] have developed a simple rabbit model of vulnerable atherosclerotic plaque, with the combination of aggressive vascular injury associated to a hyperlipidemic diet. The histological findings showed that an aortic plaque had the three features of "vulnerable plaque": lipid-rich core, accumulation of macrophages, and a thin fibrous cap. In addition, a low-density lipoprotein (LDL) receptor-deficient animal model (the WHHL rabbit) has been developed. This model resembles to human familial hypercholesterolemia and shows evidence of progressive disease of the aorta with accumulation of birefringent lipids in intimal lesions and plaques, as well as in the media from birth to 1 year of age.

Although rabbit aortic arteries are smaller in vessel diameter than human carotid artery, they allows the studies with endovascular therapeutic devices. In addition, the rabbit model has also been used for the quantification of atherosclerotic aortic component by MRI. This technique accurately quantifies fibrotic and lipid components of atherosclerosis in the model and may permit the serial analysis of therapeutic strategies on atherosclerotic plaque stabilization [41].
2.7. Porcine Models. They prevention of heart attack and stroke depends on the detection of vulnerable plaques and development of plaque-stabilizing therapies. Animal models are essential for testing mechanistic hypotheses in a controlled manner, they should be representative of a human disease, and at the same time be easy to manipulate. However, vulnerable plaque recreation is one of the toughest tasks in animal model design. Plaque rupture is an additional complication of an already complex process, and the precise mechanisms involved remain hypothetical. A plethora of experimental approaches are available for growing atherosclerotic lesions in various animal species as mentioned above (Table 2).

Currently, there is no single and golden standard animal model of vulnerable plaque, but pig models are probably the best way to recreate human plaque instability. The combination of diabetes and hypercholesterolemia constitutes a good model of accelerated atherosclerosis [42], and it was relevant study the role of certain biomarkers, such as the Lp-PLA2 since these animals share a similar plasma lipoprotein profile humans. In this regard, the selective inhibition of Lp-PLA2 by darapladib decreased progression to advanced coronary atherosclerotic lesions and confirmed a crucial role of vascular inflammation not associated to hypercholesterolemia, in the development of lesions implicated in the pathogenesis of myocardial infarction and stroke [43].

Several porcine models of advanced human-like coronary atherosclerosis have been employed to analyze the development and validation of coronary imaging technologies. In the evolving era of technological development, the availability and use of such animal models will become critical for the development of emerging technologies in interventional cardiology [44], and for the study of drugeluting stents [45]. In addition, the porcine models of coronary atherosclerosis allow examining the impact of adventitial neovascularisation, on atherosclerotic plaque composition and vascular remodelling [46].

\section{Animal Models of Abdominal Aortic Aneurysms (AAAs)}

Animal models of atherothrombotic AAA are essential tools for the preclinical evaluation of new therapeutic strategies for the suppression of aneurysmal degeneration (Table 3). Recent insights into the mechanisms of human AAA have come from the studies in mouse models, and elastaseinduced AAA in particular appears to recapitulate many features of human AAA. Here we briefly outline the most frequently used models of AAAs, and refer the reader to recent comprehensive reviews regarding additional animal models [47-52].

\subsection{Rat Models}

3.1.1. Localized Aortic Perfusion with Elastase. This model consists of exposing a segment of the abdominal aorta and infusing it with elastase [53]. The degradation of elastic fibers triggers an inflammatory response that develops into 
TABLE 2: Animal models of plaque rupture and plaque associated thrombosis.

\begin{tabular}{ll}
\hline Spontaneous & Induced \\
\hline $\begin{array}{l}\text { 39-54-month-old pigs with inherited hyper=LDL } \\
\text { cholesterolemia. }\end{array}$ & ApoE-/- mice after squeezing the aorta supplemented between forceps. \\
\hline 42-54-week old ApoE-/- mice. & Hypercholesterolemic rabbits subjected to balloon injury. \\
\hline $\begin{array}{l}\text { Dahl salt-sensitive hypertensive transgenic rats for human } \\
\text { cholesteryl ester transfer protein. }\end{array}$ & Atherosclerotic ApoE-/- mice subjected to photochemical injury. \\
\hline- & $\begin{array}{l}\text { Intraperitoneal injection of Russell's viper venom in New Zealand White } \\
\text { rabbits intermittently fed with high cholesterol diet. }\end{array}$ \\
\hline & $\begin{array}{l}\text { Intraperitoneal injection of Russel's viper venom in Watanabe heritable } \\
\text { hyperlipidemic rabbits, in combination with the administration of } \\
\text { serotonin or angiotensin II. }\end{array}$ \\
\hline
\end{tabular}

an aneurysm $[54,55]$. The severity of the induced AAA can be increased by adding plasmin to the infusion. This model has been adapted for use in several other species, including rabbit, mouse, and large animals.

3.1.2. Decellularized Xenografts. This model was based on the observation that chronic rejection of arterial allografts and xenografts, results in arterial wall dilatation and rupture. Michel and coworkers decellularized a section of abdominal aorta from one species (e.g., guinea pig), and the resulting tube of intact extracellular matrix was grafted into another morphologically compatible species, usually rat [58]. The xenogenic extracellular matrix triggers the destruction of host matrix, leading to aneurysm formation. The model has been successfully used to evaluate therapeutic targets [6469], although the heterogeneity of the aneurysms formed and the lack of vessel rupture are significant limitations.

3.2. Mouse Models. The mouse has become the preferred model for cardiovascular research for several reasons, including the ease of handling, low procedure costs, and the ability to manipulate the mouse genome. Consequently, of all animal models of AAA, mouse models have provided most of the insights into the mechanisms of human AAA. The following models are the most widely-used to date.

3.2.1. Calcium-Chloride-Induced AAA. In this method, initially developed in rabbits [62], calcium chloride is applied periaortically in the region between the renal arteries and the iliac bifurcation. Significant dilatation of the aorta is observed within 14 days, and the severity is significantly increased if calcium chloride is applied together with thioglycolate and if animals are fed a high-cholesterol diet [56]. Unlike other models, calcium chloride application induces AAA without the need for mechanical intervention.

3.2.2. Elastase-Induced AAA. The elastase-induced model was adapted for mice by Pyo et al. [57]. Elastase perfusion in mouse aorta causes a mild-to-moderate dilatation initially, which subsequently develops to a $>100 \%$ increase in aortic diameter within 14 days. In this model, the degradation of medial elastin is delayed, and the subsequent aortic wall inflammation consists of mononuclear phagocytes throughout the adventitial and medial layers, with relatively few polymorphonuclear cells localized to the adventitia [57]. Elastase-induced injury increases the expression of MMPs, cathepsins, and other proteases [70], with MMP-9 being localized to aneurysm-infiltrating macrophages [71]. Elastase-induced AAAs thus appear to recapitulate many features of human AAAs, and this model has become a valuable and convenient tool for systematically evaluating the roles of individual gene products in aneurysmal degeneration [71-80].

When compared to calcium-chloride-induced AAA, the main limitation of this method is in the mechanical stress required to recreate medial elastic degradation. However, the protocol resembles the time course of events leading to human AAA, including initial recruitment of leukocytes and mast cells, the development of a transmural aortic wall inflammatory response, and finally the upregulation of extracellular matrix metalloproteinases and other proteases, which induce a progressive degradation of the medial elastin and collagen, leading to the final aortic dilatation.

3.2.3. Angiotensin II-Induced AAA. This procedure was initially developed to define whether increased plasma concentrations of Angiotensin II (Ang II), have a direct effect on the atherogenic process in hyperlipidemic old apoE-/- mice. Unexpectedly, Ang II also produced large suprarenal abdominal aortic aneurysms in these animals [81]. In this model, inflammation of the vessel wall is associated with signaling through AT1a receptors [82], nuclear factor- (NF-) kappaBmediated induction of proinflammatory genes, including MCP-1, M-CSF, iNOS, COX-2, inhibition of PPARs [83], activation of the NADPH oxidase p47phox [84], c-JUN Nterminal [85], Rho kinases [86], and enhanced recruitment of macrophages $[87,88]$ and extracellular matrix components and degrading enzymes [89-91], leading to vessel dissection, and rupture. The severity of AAA is higher in hyperlipidemic apoE-/- or LDLR-/- male mice ( $60 \%$ of mice), when compared to normolipidemic C57Bl/6 mice, although in these models neither hyperlipidemia per se nor atherosclerosis is considered major determinants [92-94].

The model contributed to evidence the implication of the rennin-angiotensin (RAS) system in aneurysmal disease. However, two main limitations should be considered: the 
TABLE 3: Current procedures for inducing AAA in animals.

\begin{tabular}{|c|c|}
\hline Species & AAA models \\
\hline \multirow{5}{*}{ Murine } & Calcium Chloride [56]. \\
\hline & Elastase infusion [57]. \\
\hline & $\begin{array}{l}\text { Angiotensin-II-infused AAA: used in hyperlipidemic (ApoE-/- or LDLR-/-) male mice or in wild-type C57BL/6 mice in } \\
\text { conjunction with repeated administration of neutralizing TGF- } \beta \text { antibodies [50]. }\end{array}$ \\
\hline & $\begin{array}{l}\text { Decellularized xenografts: grafting of abdominal aortic extracellular matrix from one species to a compatible recipient of a } \\
\text { different species [58]. }\end{array}$ \\
\hline & Spontaneous [59]. \\
\hline \multirow{2}{*}{ Rabbit } & Elastase-induced AAA: similar to the murine model [60], also applicable to the carotid artery [61]. \\
\hline & Calcium chloride [62]. \\
\hline Pig & $\begin{array}{l}\text { Surgical model: dilatation of the infrarenal aorta with an angioplasty balloon followed by infusion of pancreatic porcine } \\
\text { elastase [63]. }\end{array}$ \\
\hline
\end{tabular}

suprarenal location of the aneurysm (in contrast to the infrarenal location in humans) and the clinical relevance of RAS inhibition, since the association of RAS in human AAA has provided controversial results, pointing towards necessary large population studies.

3.2.4. Spontaneous Mouse Mutants. The blotchy mouse is a mouse strain containing a spontaneous mutation on the $\mathrm{X}$ chromosome which leads to abnormal intestinal copper absorption. These animals have weak elastic tissue due to failed crosslinking of elastin and collagen, and develop aortic aneurysms mainly in the aortic arch, thoracic aorta, and occasionally in the abdominal aorta [59]. However, results from this model are difficult to interpret, since the mutation produces many severe additional effects.

3.3. Rabbit Models. Several of the same interventions used in mice are also implemented in rabbits, including elastase infusion [60] and calcium chloride application to the abdominal aorta [56]. Another intervention used in rabbits is elastase infusion in the right carotid artery [61]. The main advantage of rabbits over other animal models is that rabbit aneurysms more closely resemble human aneurysms hemodynamically and histologically. Rabbit models also combine several of the attractive features of small animals, such as the easy housing and handling. In addition, similarly to large animals, rabbit aneurysms can be monitored by accessing through the femoral artery, thus providing an excellent model for testing endovascular therapies $[95,96]$.

3.4. Porcine Models. Porcine models of AAA have provided significant information about the changes that occur after AAA induction and about the responses to stent deployment. A recently-developed porcine model combines mechanical dilatation by balloon angioplasty with enzymatic degradation by infusion of a collagenase/elastase solution. The model is characterized by gradual AAA expansion associated with degradation of aortic wall elastic fibers, an inflammatory cell infiltrate, and persistent smooth muscle cell loss [63]. A broad number of similarities were found between this model and human AAA, and the procedure may also represent an excellent method to evaluate endovascular related procedures. Despite the benefits, however, pigs have significant disadvantages, including complex animal handling, the requirement of special housing and surgical room facilities, the elevated cost of the animals, and the reduced sample sizes per assay.

3.5. Thoracic Aortic Aneurysm (TAA). Elastic tissue degradation is also related to the development of thoracic aortic aneurysm (TAA), and mouse models have significantly advanced the understanding of this pathology. TAA is a characteristic feature of Marfan syndrome (MFS), a disorder caused by mutations that affect the structure or expression of the extracellular matrix protein fibrillin-1, a glycoprotein that is associated of extracellular proteins, including integrin receptors and insoluble elastin [97]. Fibrillin-1 mutations in MFS decrease ECM sequestration of latent $\operatorname{TGF} \beta$, thus rendering it more prone to or accessible for activation [98100]. TAA progression in MFS is driven by elastic fiber calcification, vascular wall inflammation, intimal hyperplasia, structural collapse of the vessel wall, impaired activation of MAP kinase signaling, and altered synthesis of ECM proteins and matrix-degrading enzymes (MMPs) [101]. Systemic administration with TGF $\beta$ antagonists has been successfully used to mitigate vascular disease in mouse models of MFS and in children with severe and rapidly progressive MFS [97, 102]. Moreover, studies in mouse models have shown that fibulin-4 and LRP1 are also associated with TAA $[103,104]$.

\section{Animal Models of Heart Failure}

Models of heart disease in small animals, particularly rats, have been very useful for the assessment of pharmacological therapies. In addition, several target genes have been identified in genetically modified mouse models. Many of these genes have proved to be crucial in the initiation and progression of heart disease. Below, we describe the animal models currently used to study heart failure, which are also summarized in Table 4.

4.1. Rat Models. Rat models have dominated research into heart damage because, while rats share many of the benefits of mice (low cost, ease of handling, etc.), their larger 
TABLE 4: Current procedures for inducing heart damage in animals.

\begin{tabular}{ll}
\hline Species & Heart failure models \\
\hline & Myocardial damage \\
& Chemical: isoproterenol administration [106]. \\
& Electrical: overlapping burns [107]. \\
& Surgical: coronary artery ligation [105]. \\
Ischemia Reperfusion: & Transient occlusion of the left coronary artery [108]. \\
& Cryoinfarction: cryo-injuries to the epicardium [109]. \\
& Pressure overload: aortic constriction and banding. Aortic stenosis [110, 111]. \\
& Transgenic models of dilated cardiomyopathy: mutation of cardiac $\alpha$-actin protein [112]. \\
& Spontaneous: WHHLMI rabbits [113]. \\
& Coronary artery occlusion: similar to the murine model, also applicable to the carotid artery. This is an excellent \\
Rabbit & model for testing endovascular therapies [114]. \\
& Pressure overload: aortic banding [115], valvular stenosis [116]. \\
& Microembolization [117]. \\
& Tachycardia: ventricular pacing [118]. \\
& Aortic stenosis [119]. \\
Dog & Surgical model: balloon occlusion of coronary arteries [120]. \\
& Tachycardia: pacing-induced supraventricular tachycardia [121]. \\
\hline Pig &
\end{tabular}

size greatly facilitates surgical and postsurgical procedures. Myocardial damage in rat hearts is induced by three procedures: surgical, pharmacological, or electrical.

The surgical method, first developed by Pfeffer and coworkers, consists of ligating the left coronary artery [105]. In this procedure, left thoracotomy is performed on the anesthetized rat, and the heart is rapidly exteriorized by gentle pressure on the right side of the thorax. The left coronary artery is either ligated or heat cauterized between the pulmonary artery outflow tract and the left atrium. The heart is then returned to its normal position and the thorax immediately closed. Several modifications have been introduced to improve performance and to reduce animal mortality, and left coronary artery ligation is the most common method used to induce acute myocardial damage in rat and other animal models. One important modification is temporary occlusion followed by reperfusion, allowing flow recovery through the previously occluded coronary artery bed. Left coronary artery ligation can thus be used to evaluate diverse parameters resulting from either permanent ischemia or ischemia/reperfusion.

Pharmacological induction of heart damage was first implemented by Bagdon and coworkers in 1963 and is achieved by treatment with the beta-one adrenergic receptor (B-AR) agonist isoproterenol [106]. Isoproterenol administration before ischemia exerts a cardioprotective action in rats, but at the right dose it induces cardiac myocyte necrosis and extensive LV dilatation and hypertrophy.

Isoproterenol treatment and left coronary artery ligation in rats are efficient and reproducible methods that provide valuable information about the underlying mechanisms implicated in human heart disease.

The electrical method consists of generating overlapping burns in exposed rat hearts by applying a 2-mm-tipped soldering iron to the epicardium of the left ventricle [107].
While this is also a valid method, the degree of heart damage produced is not consistent among laboratories, limiting the reproducibility of the results obtained with this procedure.

4.2. Mouse Models. Against the many general advantages of working with mice (ease of handling, low pregnancy times, etc.), investigators choosing them as models of heart failure must consider two important limitations: the small size of the heart and the structural differences with respect to the human cardiovascular system. Nonetheless, the availability of transgenic and knockout strains and the relative ease with which new genetic modifications can be introduced make the mouse one of the most attractive models for research into the molecular basis of heart failure.

One of the most widely used models of heart failure in mice is the left coronary artery ligation procedure, adapted from rat. In some protocols the artery is occluded permanently, but recently procedures for temporary occlusion have been introduced to reproduce human ischemia/reperfusion injury [108]. In this method the left anterior descending coronary artery is occluded and then reperfused, allowing flow recovery through the previously occluded coronary artery bed. Reperfusion is monitored visually, and the infarct can be analyzed by histopathological techniques, and can be documented in real time by non invasive high frequency. The areas at risk and the infarct size are revealed by staining with Evans blue dye and triphenyltetrazolium chloride and are assessed by computerized planimetry. This model has confirmed the benefits of reperfusion, since infarct size was found to be significantly lower than after permanent occlusion of the coronary artery.

The method has been further modified to analyze ischemic preconditioning of the heart. In this method, the left coronary artery is repeatedly occluded to subject the heart to several rounds of brief ischemia and reperfusion, 
followed by permanent occlusion. This approach has identified several ischemia-induced genes that confer tolerance to a subsequent ischemic event [122].

More recently, a model of myocardial infarction was developed, in mice and rats, in which a series of cryoinjuries is generated in the heart. This new model is yielding promising results [109].

4.3. Large Animal Models of Heart Failure. Small animal models have provided significant insights into human cardiac pathophysiology. However, rodent and human hearts differ in their architecture, heart rates, oxygen consumption, contractility, protein expression, and even stem cell populations, and there is therefore an obvious need for models of heart failure in large animals.

The first large animals used to study heart failure were dogs, in which models of myocardial infarction and serial microembolization of the coronary artery were developed [117]. However, the preferred large animal model of heart damage is the pig, because the collateral coronary circulation and arterial anatomy of pigs and humans are very similar and infarct size can be accurately predicted [123]. Among several models of MI in pigs, one of the most widely used is balloon occlusion of the left anterior descending coronary artery. In this model, a catheter is inserted through the femoral artery, positioning an angioplasty balloon over a guide wire at a position distal to the second largest diagonal branch of the artery, and infarction is induced by balloon inflation [120]. The similar size and cardiac physiology of pigs and humans mean that this model offers major advantages over models in other species. However, the method requires specialized equipment, dedicated surgical facilities and skilled personnel, limiting the number of laboratories able to conduct these studies.

The rabbit, much less expensive than pig, offers a compromise solution. Rabbit models of heart failure, including coronary artery occlusion models [114], have major advantages over other species. For example, the composition of sarcomeric proteins in rabbits is similar to that in humans, and the sarcolemmic reticulum contributes about $70 \%$ of calcium elimination. In addition, the WHHLMI rabbit strain provides a model of spontaneous myocardial infarction requiring no surgical intervention. This model was developed by selective breeding of coronary atherosclerosisprone WHHL rabbits [124]. The main limitation of the WHHLMI model is that it does not feature plaque rupture, whereas in humans coronary plaque rupture and subsequent intravascular thrombosis are the major causes of acute myocardial infarction. Despite this limitation, the model is valid for the study of atherosclerosis-related heart complications $[113,125]$.

An additional model of heart failure in large and small animals is pressure overload of the left ventricle, induced by transverse aortic constriction in mice [110] and aortic banding in rats and rabbits. Left ventricle hypertrophy can also be recreated by ventricular pacing in dogs $[115,118$, 126], valvular stenosis in rabbits [116], and renal artery constriction or aortic stenosis in rats, hamsters, mice, rabbits and dogs [111, 119].
Another model of heart failure is the dilated cardiomyopathy. Human dilated cardiomyopathy has been modeled in rabbits and pigs by inducing chronic tachycardia with a pacemaker [121, 127]. Transgenic mouse models, involving mutations that predispose to dilated cardiomyopathy, have also proved very useful. These models have identified an association of cytoskeletal and contractile proteins with this pathology, and very recently a transgenic model expressing a mutated cardiac alpha-actin gene was provided, in which calcium sensitivity of myofilaments is decreased and the expression of calcium/calmodulin-dependent kinase IIdelta (CaMKIIdelta) is increased [112]. Inhibition of CaMKIIdelta in these animals prevented the increase in p53 and apoptotic cardiomyocytes and ameliorated cardiac function.

\section{Conclusion}

Animal models of cardiovascular disease yield important insights into the genetic basis of human cardiovascular diseases and provide a test bed for pharmacological and treatments. Nonetheless, investigators need to carefully consider their choice of model: no single method perfectly recreates the human disease, and there are related considerations of cost, infrastructure and the requirement for specialized personnel. Taking these considerations into account, experimenters therefore need to select models that best reproduce the aspect of disease being investigated. In particular, when moving from bench to bedside it is essential to test procedures in relevant models that yield highly reproducible results, but despite these limitations, given the range of animal models available today it will always be possible to devise an appropriate strategy, and animal models remain the best tools for advancing the understanding of the mechanism of human cardiovascular disease.

\section{Acknowledgments}

Authors' work has been supported by Ministerio de Ciencia y Tecnología (SAF2007/63648, SAF2008/04629, SAF2009/11749, PI10/00072), CAM (S2006/GEN-0247), FIS (RECAVA RD06/0014/0035, PS09/00447), European Network (HEALTH F2-2008-200647), Euro Salud EUS200503565 and cvREMOD 091100. C. Zaragoza and C. GomezGuerrero contributed equally.

\section{References}

[1] G. S. Getz and C. A. Reardon, "Diet and murine atherosclerosis," Arteriosclerosis, Thrombosis, and Vascular Biology, vol. 26, no. 2, pp. 242-249, 2006.

[2] K. S. Meir and E. Leitersdorf, "Atherosclerosis in the apolipoprotein E-deficient mouse: a decade of progress," Arteriosclerosis, Thrombosis, and Vascular Biology, vol. 24, no. 6, pp. 1006-1014, 2004.

[3] S. C. Whitman, "A practical approach to using mice in atherosclerosis research," The Clinical Biochemist Reviews, vol. 25, pp. 81-93, 2004.

[4] S. Zadelaar, R. Kleemann, L. Verschuren et al., "Mouse models for atherosclerosis and pharmaceutical modifiers," 
Arteriosclerosis, Thrombosis, and Vascular Biology, vol. 27, no. 8, pp. 1706-1721, 2007.

[5] S. Ishibashi, M. S. Brown, J. L. Goldstein, R. D. Gerard, R. E. Hammer, and J. Herz, "Hypercholesterolemia in low density lipoprotein receptor knockout mice and its reversal by adenovirus-mediated gene delivery," Journal of Clinical Investigation, vol. 92, no. 2, pp. 883-893, 1993.

[6] J. F. Bentzon and E. Falk, "Atherosclerotic lesions in mouse and man: is it the same disease?" Current Opinion in Lipidology, vol. 21, no. 5, pp. 434-440, 2010.

[7] J. W. Knowles and N. Maeda, "Genetic modifiers of atherosclerosis in mice," Arteriosclerosis, Thrombosis, and Vascular Biology, vol. 20, no. 11, pp. 2336-2345, 2000.

[8] L. Powell-Braxton, M. Véniant, R. D. Latvala et al., "A mouse model of human familial hypercholesterolemia: markedly elevated low density lipoprotein cholesterol levels and severe atherosclerosis on a low-fat chow diet," Nature Medicine, vol. 4, no. 8, pp. 934-938, 1998.

[9] M. M. Véniant, C. H. Zlot, R. L. Walzem et al., "Lipoprotein clearance mechanisms in LDL receptor-deficient "Apo-B48only" and "Apo-B100-only" mice," Journal of Clinical Investigation, vol. 102, no. 8, pp. 1559-1568, 1998.

[10] A. H. Hasty, H. Shimano, J. I. Osuga et al., "Severe hypercholesterolemia, hypertriglyceridemia, and atherosclerosis in mice lacking both leptin and the low density lipoprotein receptor," Journal of Biological Chemistry, vol. 276, no. 40, pp. 37402-37408, 2001.

[11] D. A. Sanan, D. L. Newland, R. Tao et al., "Low density lipoprotein receptor-negative mice expressing human apolipoprotein B-100 develop complex atherosclerotic lesions on a chow diet: no accentuation by apolipoprotein," Proceedings of the National Academy of Sciences of the United States of America, vol. 95, no. 8, pp. 4544-4549, 1998.

[12] S. Bonthu, D. D. Heistad, D. A. Chappell, K. G. Lamping, and F. M. Faraci, "Atherosclerosis, vascular remodeling, and impairment of endothelium- dependent relaxation in genetically altered hyperlipidemic mice," Arteriosclerosis, Thrombosis, and Vascular Biology, vol. 17, no. 11, pp. 23332340, 1997.

[13] J. Jawień, P. Nastałek, and R. Korbut, "Mouse models of experimental atherosclerosis," Journal of Physiology and Pharmacology, vol. 55, no. 3, pp. 503-517, 2004.

[14] Z. Chen, T. Fukutomi, A. C. Zago et al., "Simvastatin reduces neointimal thickening in low-density lipoprotein receptordeficient mice after experimental angioplasty without changing plasma lipids," Circulation, vol. 106, no. 1, pp. 20-23, 2002.

[15] A. C. Li, K. K. Brown, M. J. Silvestre, T. M. Willson, W. Palinski, and C. K. Glass, "Peroxisome proliferator-activated receptor $\gamma$ ligands inhibit development of atherosclerosis in LDL receptor-deficient mice," Journal of Clinical Investigation, vol. 106, no. 4, pp. 523-531, 2000.

[16] N. Terasaka, A. Hiroshima, T. Koieyama et al., “T-0901317, a synthetic liver X receptor ligand, inhibits development of atherosclerosis in LDL receptor-deficient mice," FEBS Letters, vol. 536, no. 1-3, pp. 6-11, 2003.

[17] S. H. Zhang, R. L. Reddick, J. A. Piedrahita, and N. Maeda, "Spontaneous hypercholesterolemia and arterial lesions in mice lacking apolipoprotein E," Science, vol. 258, no. 5081, pp. 468-471, 1992.

[18] A. S. Plump, J. D. Smith, T. Hayek et al., "Severe hypercholesterolemia and atherosclerosis in apolipoprotein E- deficient mice created by homologous recombination in ES cells," Cell, vol. 71, no. 2, pp. 343-353, 1992.
[19] S. H. Zhang, R. L. Reddick, B. Burkey, and N. Maeda, "Diet-induced atherosclerosis in mice heterozygous and homozygous for apolipoprotein E gene disruption," Journal of Clinical Investigation, vol. 94, no. 3, pp. 937-945, 1994.

[20] Y. Nakashima, A. S. Plump, E. W. Raines, J. L. Breslow, and R. Ross, "ApoE-deficient mice develop lesions of all phases of atherosclerosis throughout the arterial tree," Arteriosclerosis and Thrombosis, vol. 14, no. 1, pp. 133-140, 1994.

[21] W. Hu, P. Polinsky, E. Sadoun, M. E. Rosenfeld, and S. M. Schwartz, "Atherosclerotic lesions in the common coronary arteries of ApoE knockout mice," Cardiovascular Pathology, vol. 14, no. 3, pp. 120-125, 2005.

[22] R. L. Reddick, S. H. Zhang, and N. Maeda, "Atherosclerosis in mice lacking apo E: evaluation of lesional development and progression," Arteriosclerosis and Thrombosis, vol. 14, no. 1, pp. 141-147, 1994.

[23] Y. X. Wang, B. Martin-McNulty, L. Y. Huw et al., "Antiatherosclerotic effect of simvastatin depends on the presence of apolipoprotein E," Atherosclerosis, vol. 162, no. 1, pp. 23$31,2002$.

[24] J. Johnson, K. Carson, H. Williams et al., "Plaque rupture after short periods of fat feeding in the apolipoprotein E-knockout mouse: model characterization and effects of pravastatin treatment," Circulation, vol. 111, no. 11, pp. 1422-1430, 2005.

[25] J. Grönros, J. Wikström, U. Brandt-Eliasson et al., "Effects of rosuvastatin on cardiovascular morphology and function in an ApoE-knockout mouse model of atherosclerosis," American Journal of Physiology, vol. 295, no. 5, pp. H2046H2053, 2008.

[26] Z. Chen, S. Ishibashi, S. Perrey et al., "Troglitazone inhibits atherosclerosis in apolipoprotein E-knockout mice: pleiotropic effects on CD36 expression and HDL," Arteriosclerosis, Thrombosis, and Vascular Biology, vol. 21, no. 3, pp. 372-377, 2001.

[27] A. C. Calkin, T. J. Allen, M. Lassila, C. Tikellis, K. A. JandeleitDahm, and M. C. Thomas, "Increased atherosclerosis following treatment with a dual PPAR agonist in the ApoE knockout mouse," Atherosclerosis, vol. 195, no. 1, pp. 17-22, 2007.

[28] B. Trigatti, H. Rayburn, M. Viñals et al., "Influence of the high density lipoprotein receptor SR-BI on reproductive and cardiovascular pathophysiology," Proceedings of the National Academy of Sciences of the United States of America, vol. 96, no. 16, pp. 9322-9327, 1999.

[29] A. Yesilaltay, K. Daniels, R. Pal, M. Krieger, and O. Kocher, "Loss of PDZK1 causes coronary artery occlusion and myocardial infarction in Paigen diet-fed apolipoprotein E deficient mice," PloS one, vol. 4, no. 12, Article ID e8103, 2009.

[30] M. H. Hofker, B. J. M. Van Vlijmen, and L. M. Havekes, "Transgenic mouse models to study the role of APOE in hyperlipidemia and atherosclerosis," Atherosclerosis, vol. 137, no. 1, pp. 1-11, 1998.

[31] P. Leppänen, J. S. Luoma, M. H. Hofker, L. M. Havekes, and S. Ylä-Herttuala, "Characterization of atherosclerotic lesions in apo E3-leiden transgenic mice," Atherosclerosis, vol. 136, no. 1, pp. 147-152, 1998.

[32] J. W. A. Van Der Hoorn, J. W. Jukema, L. M. Havekes et al., "The dual PPAR $\alpha / \gamma$ agonist tesaglitazar blocks progression of pre-existing atherosclerosis in APOE* 3 Leiden.CETP transgenic mice," British Journal of Pharmacology, vol. 156, no. 7, pp. 1067-1075, 2009. 
[33] P. Reaven, S. Merat, F. Casanada, M. Sutphin, and W. Palinski, "Effect of streptozotocin-induced hyperglycemia on lipid profiles, formation of advanced glycation endproducts in lesions, and extent of atherosclerosis in LDL receptordeficient mice," Arteriosclerosis, Thrombosis, and Vascular Biology, vol. 17, no. 10, pp. 2250-2256, 1997.

[34] X. Shen and K. E. Bornfeldt, "Mouse models for studies of cardiovascular complications of type 1 diabetes," Annals of the New York Academy of Sciences, vol. 1103, pp. 202-217, 2007.

[35] T. Hayek, K. Hussein, M. Aviram et al., "Macrophagefoam cell formation in streptozotocin-induced diabetic mice: stimulatory effect of glucose," Atherosclerosis, vol. 183, no. 1, pp. 25-33, 2005.

[36] D. B. Weinreb, J. G. S. Aguinaldo, J. E. Feig, E. A. Fisher, and Z. A. Fayad, "Non-invasive MRI of mouse models of atherosclerosis," NMR in Biomedicine, vol. 20, no. 3, pp. 256264, 2007.

[37] M. Aikawa, S. Sugiyama, C. C. Hill et al., "Lipid lowering reduces oxidative stress and endothelial cell activation in rabbit atheroma," Circulation, vol. 106, no. 11, pp. 13901396, 2002.

[38] C. Bustos, M. A. Hernández-Presa, M. Ortego et al., "HMGCoA reductase inhibition by atorvastatin reduces neointimal inflammation in a rabbit model of atherosclerosis," Journal of the American College of Cardiology, vol. 32, no. 7, pp. 20572064, 1998.

[39] R. Largo, O. Sánchez-Pernaute, M. E. Marcos et al., "Chronic arthritis aggravates vascular lesions in rabbits with atherosclerosis: a novel model of atherosclerosis associated with chronic inflammation," Arthritis and Rheumatism, vol. 58, no. 9, pp. 2723-2734, 2008.

[40] T. Shimizu, K. Nakai, Y. Morimoto et al., "Simple rabbit model of vulnerable atherosclerotic plaque," Neurologia Medico-Chirurgica, vol. 49, no. 8, pp. 327-332, 2009.

[41] G. Helft, S. G. Worthley, V. Fuster et al., "Atherosclerotic aortic component quantification by noninvasive magnetic resonance imaging: an in vivo study in rabbits," Journal of the American College of Cardiology, vol. 37, no. 4, pp. 1149-1154, 2001.

[42] R. G. Gerrity, R. Natarajan, J. L. Nadler, and T. Kimsey, "Diabetes-induced accelerated atherosclerosis in swine," Diabetes, vol. 50, no. 7, pp. 1654-1665, 2001.

[43] R. L. Wilensky, Y. I. Shi, E. R. Mohler et al., "Inhibition of lipoprotein-associated phospholipase A reduces complex coronary atherosclerotic plaque development," Nature Medicine, vol. 14, no. 10, pp. 1059-1066, 2008.

[44] J. F. Granada, G. L. Kaluza, R. L. Wilensky, B. C. Biedermann, R. S. Schwartz, and E. Falk, "Porcine models of coronary atherosclerosis and vulnerable plaque for imaging and interventional research," EuroIntervention, vol. 5, no. 1, pp. 140$148,2009$.

[45] N. Hamada, M. Miyata, H. Eto et al., "Tacrolimus-eluting stent inhibits neointimal hyperplasia via calcineurin/NFAT signaling in porcine coronary artery model," Atherosclerosis, vol. 208, no. 1, pp. 97-103, 2010.

[46] C. L. Alviar, A. Tellez, D. Wallace-Bradley et al., "Impact of adventitial neovascularisation on atherosclerotic plaque composition and vascular remodelling in a porcine model of coronary atherosclerosis," EuroIntervention, vol. 5, no. 8, pp. 981-988, 2010.

[47] P. B. Dobrin, "Basic science: animal models of aneurysms," Annals of Vascular Surgery, vol. 13, no. 6, pp. 641-648, 1999.
[48] T. W. G. Carrell, A. Smith, and K. G. Burnand, "Experimental techniques and models in the study of the development and treatment of abdominal aortic aneurysm," British Journal of Surgery, vol. 86, no. 3, pp. 305-312, 1999.

[49] R. W. Thompson, P. J. Geraghty, and J. K. Lee, "Abdominal aortic aneurysms: basic mechanisms and clinical implications," Current Problems in Surgery, vol. 39, no. 2, pp. 110230, 2002.

[50] A. Daugherty and L. A. Cassis, "Mouse models of abdominal aortic aneurysms," Arteriosclerosis, Thrombosis, and Vascular Biology, vol. 24, no. 3, pp. 429-434, 2004.

[51] R. A. Chaer, B. G. DeRubertis, R. Hynecek, K. C. Kent, and P. L. Faries, "Models of abdominal aortic aneurysm: characterization and clinical applications," Vascular, vol. 14, no. 6, pp. 343-352, 2006.

[52] S. Annambhotla, S. Bourgeois, X. Wang, P. H. Lin, Q. Yao, and C. Chen, "Recent advances in molecular mechanisms of abdominal aortic aneurysm formation," World Journal of Surgery, vol. 32, no. 6, pp. 976-986, 2008.

[53] K. I. Paraskevas, D. P. Mikhailidis, and D. Perrea, "Experimental models of abdominal aortic aneurysms: an overview," Current Pharmaceutical Design, vol. 14, no. 4, pp. 325-337, 2008.

[54] S. Anidjar, J. L. Salzmann, D. Gentric, P. Lagneau, J. P. Camilleri, and J. B. Michel, "Elastase-induced experimental aneurysms in rats," Circulation, vol. 82, no. 3, pp. 973-981, 1990.

[55] S. Anidjar, P. B. Dobrin, M. Eichorst, G. P. Graham, and G. Chejfec, "Correlation of inflammatory infiltrate with the enlargement of experimental aortic aneurysms," Journal of Vascular Surgery, vol. 16, no. 2, pp. 139-147, 1992.

[56] T. Freestone, R. J. Turner, D. J. Higman, M. J. Lever, and J. T. Powell, "Influence of hypercholesterolemia and adventitial inflammation on the development of aortic aneurysm in rabbits," Arteriosclerosis, Thrombosis, and Vascular Biology, vol. 17, no. 1, pp. 10-17, 1997.

[57] R. Pyo, J. K. Lee, J. M. Shipley et al., "Targeted gene disruption of matrix metalloproteinase-9 (gelatinase B) suppresses development of experimental abdominal aortic aneurysms," Journal of Clinical Investigation, vol. 105, no. 11, pp. 16411649, 2000.

[58] E. Allaire, C. Guettier, P. Bruneval, D. Plissonnier, and J. B. Michel, "Cell-free arterial grafts: morphologic characteristics of aortic isografts, allografts, and xenografts in rats," Journal of Vascular Surgery, vol. 19, no. 3, pp. 446-456, 1994.

[59] C. M. Brophy, J. E. Tilson, I. M. Braverman, and M. D. Tilson, "Age of onset, pattern of distribution, and histology of aneurysm development in a genetically predisposed mouse model," Journal of Vascular Surgery, vol. 8, no. 1, pp. 45-48, 1988.

[60] M. Matsushita, H. Kobayashi, K. Oda, N. Nishikimi, T. Sakurai, and Y. Nimura, "A rabbit model of abdominal aortic aneurysm associated with intimal thickening," European Surgical Research, vol. 31, no. 4, pp. 305-313, 1999.

[61] N. H. Fujiwara, H. J. Cloft, W. F. Marx, J. G. Short, M. E. Jensen, and D. F. Kallmes, "Serial angiography in an elastaseinduced aneurysm model in rabbits: evidence for progressive aneurysm enlargement after creation," American Journal of Neuroradiology, vol. 22, no. 4, pp. 698-703, 2001.

[62] S. D. Gertz, A. Kurgan, and D. Eisenberg, "Aneurysm of the rabbit common carotid artery induced by periarterial application of calcium chloride in vivo," Journal of Clinical Investigation, vol. 81, no. 3, pp. 649-656, 1988. 
[63] J. Moláček, V. Třeška, J. Kobr et al., "Optimization of the model of abdominal aortic aneurysm-experiment in an animal model," Journal of Vascular Research, vol. 46, no. 1, pp. 1-5, 2008.

[64] E. Allaire, R. Forough, M. Clowes, B. Starcher, and A. W. Clowes, "Local overexpression of TIMP-1 prevents aortic aneurysm degeneration and rupture in a rat model," Journal of Clinical Investigation, vol. 102, no. 7, pp. 1413-1420, 1998.

[65] E. Allaire, D. Hasenstab, R. D. Kenagy, B. Starcher, M. M. Clowes, and A. W. Clowes, "Prevention of aneurysm development and rupture by local overexpression of plasminogen activator inhibitor-1," Circulation, vol. 98, no. 3, pp. 249-255, 1998.

[66] E. Allaire, B. Muscatelli-Groux, C. Mandet et al., "Paracrine effect of vascular smooth muscle cells in the prevention of aortic aneurysm formation," Journal of Vascular Surgery, vol. 36, no. 5, pp. 1018-1026, 2002.

[67] L. Sarda-Mantel, M. Coutard, F. Rouzet et al., "Tc-annexin$\mathrm{V}$ functional imaging of luminal thrombus activity in abdominal aortic aneurysms," Arteriosclerosis, Thrombosis, and Vascular Biology, vol. 26, no. 9, pp. 2153-2159, 2006.

[68] Z. Touat, V. Ollivier, J. Dai et al., "Renewal of mural thrombus releases plasma markers and is involved in aortic abdominal aneurysm evolution," American Journal of Pathology, vol. 168, no. 3, pp. 1022-1030, 2006.

[69] J. Dai, L. Louedec, M. Philippe, J. B. Michel, and X. Houard, "Effect of blocking platelet activation with AZD6140 on development of abdominal aortic aneurysm in a rat aneurysmal model," Journal of Vascular Surgery, vol. 49, no. 3, pp. 719-727, 2009.

[70] T. R. Lizarbe, C. Tarín, M. Gómez et al., "Nitric oxide induces the progression of abdominal aortic aneurysms through the matrix metalloproteinase inducer EMMPRIN," American Journal of Pathology, vol. 175, no. 4, pp. 1421-1430, 2009.

[71] R. W. Thompson, J. A. Curci, T. L. Ennis, D. Mao, M. B. Pagano, and C. T. N. Pham, "Pathophysiology of abdominal aortic aneurysms: insights from the elastase-induced model in mice with different genetic backgrounds," Annals of the New York Academy of Sciences, vol. 1085, pp. 59-73, 2006.

[72] J. K. Lee, M. Borhani, T. L. Ennis, G. R. Upchurch, and R. W. Thompson, "Experimental abdominal aortic aneurysms in mice lacking expression of inducible nitric oxide synthase," Arteriosclerosis, Thrombosis, and Vascular Biology, vol. 21, no. 9, pp. 1393-1401, 2001.

[73] E. Sho, M. Sho, H. Nanjo, K. Kawamura, H. Masuda, and R. L. Dalman, "Hemodynamic regulation of CD34 cell localization and differentiation in experimental aneurysms," Arteriosclerosis, Thrombosis, and Vascular Biology, vol. 24, no. 10, pp. 1916-1921, 2004.

[74] J. L. Eliason, K. K. Hannawa, G. Ailawadi et al., "Neutrophil depletion inhibits experimental abdominal aortic aneurysm formation," Circulation, vol. 112, no. 2, pp. 232-240, 2005.

[75] F. E. Parodi, D. Mao, T. L. Ennis, M. A. Bartoli, and R. W. Thompson, "Suppression of experimental abdominal aortic aneurysms in mice by treatment with pyrrolidine dithiocarbamate, an antioxidant inhibitor of nuclear factor$\kappa \mathrm{B}$," Journal of Vascular Surgery, vol. 41, no. 3, pp. 479-489, 2005.

[76] E. F. Steinmetz, C. Buckley, M. L. Shames et al., “Treatment with simvastatin suppresses the development of experimental abdominal aortic aneurysms in normal and hypercholesterolemic mice," Annals of Surgery, vol. 241, no. 1, pp. 92-101, 2005.
[77] S. J. Van Vickle-Chavez, W. S. Tung, T. S. Absi et al., "Temporal changes in mouse aortic wall gene expression during the development of elastase-induced abdominal aortic aneurysms," Journal of Vascular Surgery, vol. 43, no. 5, pp. 1010-1020, 2006.

[78] M. B. Pagano, M. A. Bartoli, T. L. Ennis et al., "Critical role of dipeptidyl peptidase I in neutrophil recruitment during the development of experimental abdominal aortic aneurysms," Proceedings of the National Academy of Sciences of the United States of America, vol. 104, no. 8, pp. 2855-2860, 2007.

[79] J. Sun, G. K. Sukhova, M. Yang et al., "Mast cells modulate the pathogenesis of elastase-induced abdominal aortic aneurysms in mice," Journal of Clinical Investigation, vol. 117, no. 11, pp. 3359-3368, 2007.

[80] M. B. Pagano, H. F. Zhou, T. L. Ennis et al., "Complementdependent neutrophil recruitment is critical for the development of elastase-induced abdominal aortic aneurysm," Circulation, vol. 119, no. 13, pp. 1805-1813, 2009.

[81] A. Daugherty, M. W. Manning, and L. A. Cassis, "Angiotensin II promotes atherosclerotic lesions and aneurysms in apolipoprotein E-deficient mice," Journal of Clinical Investigation, vol. 105, no. 11, pp. 1605-1612, 2000.

[82] L. A. Cassis, D. L. Rateri, H. Lu, and A. Daugherty, "Bone marrow transplantation reveals that recipient AT1a receptors are required to initiate angiotensin II-induced atherosclerosis and aneurysms," Arteriosclerosis, Thrombosis, and Vascular Biology, vol. 27, no. 2, pp. 380-386, 2007.

[83] D. M. Tham, B. Martin-McNulty, YI. X. Wang et al., "Angiotensin II is associated with activation of NF- $\kappa \mathrm{B}$ mediated genes and downregulation of PPARs," Physiological Genomics, vol. 11, pp. 21-30, 2003.

[84] M. Thomas, D. Gavrila, M. L. McCormick et al., "Deletion of p47 attenuates angiotensin II-induced abdominal aortic aneurysm formation in apolipoprotein E-deficient mice," Circulation, vol. 114, no. 5, pp. 404-413, 2006.

[85] K. Yoshimura, H. Aoki, Y. Ikeda et al., "Regression of abdominal aortic aneurysm by inhibition of c-Jun Nterminal kinase," Nature Medicine, vol. 11, no. 12, pp. 13301338, 2005.

[86] YI. X. Wang, B. Martin-McNulty, V. Da Cunha et al., "Fasudil, a Rho-kinase inhibitor, attenuates angiotensin IIinduced abdominal aortic aneurysm in apolipoprotein Edeficient mice by inhibiting apoptosis and proteolysis," Circulation, vol. 111, no. 17, pp. 2219-2226, 2005.

[87] K. Saraff, F. Babamusta, L. A. Cassis, and A. Daugherty, "Aortic dissection precedes formation of aneurysms and atherosclerosis in angiotensin II-infused, apolipoprotein Edeficient mice," Arteriosclerosis, Thrombosis, and Vascular Biology, vol. 23, no. 9, pp. 1621-1626, 2003.

[88] M. Ishibashi, K. Egashira, Q. Zhao et al., "Bone marrow-derived monocyte chemoattractant protein1 receptor CCR2 is critical in angiotensin II-induced acceleration of atherosclerosis and aneurysm formation in hypercholesterolemic mice," Arteriosclerosis, Thrombosis, and Vascular Biology, vol. 24, no. 11, pp. e174-178, 2004.

[89] M. W. Manning, L. A. Cassis, and A. Daugherty, "Differential effects of doxycycline, a broad-spectrum matrix metalloproteinase inhibitor, on angiotensin II-induced atherosclerosis and abdominal aortic aneurysms," Arteriosclerosis, Thrombosis, and Vascular Biology, vol. 23, no. 3, pp. 483-488, 2003.

[90] G. G. Deng, B. Martin-McNulty, D. A. Sukovich et al., "Urokinase-type plasminogen activator plays a critical role in angiotensin II-induced abdominal aortic aneurysm," Circulation Research, vol. 92, no. 5, pp. 510-517, 2003. 
[91] J. O. Deguchi, H. Huang, P. Libby et al., "Genetically engineered resistance for MMP collagenases promotes abdominal aortic aneurysm formation in mice infused with angiotensin II," Laboratory Investigation, vol. 89, no. 3, pp. 315-326, 2009.

[92] V. L. King, A. Y. Lin, F. Kristo et al., "Interferon- $\gamma$ and the interferon-inducible chemokine CXCL10 protect against aneurysm formation and rupture," Circulation, vol. 119, no. 3, pp. 426-435, 2009.

[93] G. Nickenig, O. Jung, K. Strehlow et al., "Hypercholesterolemia is associated with enhanced angiotensin ATreceptor expression," American Journal of Physiology, vol. 272, no. 6, pp. H2701-H2707, 1997.

[94] L. A. Cassis, M. Gupte, S. Thayer et al., "ANG II infusion promotes abdominal aortic aneurysms independent of increased blood pressure in hypercholesterolemic mice," American Journal of Physiology, vol. 296, no. 5, pp. H1660H1665, 2009.

[95] D. Dai, Y. H. Ding, D. A. Lewis, and D. F. Kallmes, "A proposed ordinal scale for grading histology in elastase-induced, saccular aneurysms," American Journal of Neuroradiology, vol. 27, no. 1, pp. 132-138, 2006.

[96] D. Dai, Y. H. Ding, M. A. Danielson et al., "Endovascular treatment of experimental aneurysms with use of fibroblast transfected with replication-deficient adenovirus containing bone morphogenetic protein-13 gene," American Journal of Neuroradiology, vol. 29, no. 4, pp. 739-744, 2008.

[97] F. Ramirez and H. C. Dietz, "Marfan syndrome: from molecular pathogenesis to clinical treatment," Current Opinion in Genetics and Development, vol. 17, no. 3, pp. 252-258, 2007.

[98] E. R. Neptune, P. A. Frischmeyer, D. E. Arking et al., "Dysregulation of TGF- $\beta$ activation contributes to pathogenesis in Marfan syndrome," Nature Genetics, vol. 33, no. 3, pp. 407411, 2003.

[99] C. M. Ng, A. Cheng, L. A. Myers et al., “TGF- $\beta$-dependent pathogenesis of mitral valve prolapse in a mouse model of Marfan syndrome," Journal of Clinical Investigation, vol. 114, no. 11, pp. 1586-1592, 2004.

[100] J. P. Habashi, D. P. Judge, T. M. Holm et al., "Losartan, an AT1 antagonist, prevents aortic aneurysm in a mouse model of Marfan syndrome," Science, vol. 312, no. 5770, pp. 117 121, 2006.

[101] L. Carta, S. Smaldone, L. Zilberberg et al., "p38 MAPK is an early determinant of promiscuous $\operatorname{Smad} 2 / 3$ signaling in the aortas of fibrillin-1 (Fbn1)-null mice," Journal of Biological Chemistry, vol. 284, no. 9, pp. 5630-5636, 2009.

[102] B. S. Brooke, J. P. Habashi, D. P. Judge, N. Patel, B. Loeys, and H. C. Dietz, "Angiotensin II blockade and aortic-root dilation in marfan's syndrome," New England Journal of Medicine, vol. 358, no. 26, pp. 2787-2795, 2008.

[103] P. Boucker, W.-P. Li, R. L. Matz et al., "LRP1 functions as an atheroprotective integrator of TGF $\beta$ and PDGF signals in the vascular wall: implications for Marfan syndrome," PLoS ONE, vol. 2, no. 5, article e448, 2007.

[104] K. Hanada, M. Vermeij, G. A. Garinis et al., "Perturbations of vascular homeostasis and aortic valve abnormalities in fibulin-4 deficient mice," Circulation Research, vol. 100, no. 5, pp. 738-746, 2007.

[105] M. A. Pfeffer, J. M. Pfeffer, and M. C. Fishbein, "Myocardial infarct size and ventricular function in rats," Circulation Research, vol. 44, no. 4, pp. 503-512, 1979.

[106] G. Zbinden and R. E. Bagdon, "Isoproterenol-induced heart necrosis, an experimental model for the study of angina pectoris and myocardial infarct," Reviews of Canadian Biology, vol. 22, pp. 257-263, 1963.
[107] N. Adler, L. L. Camin, and P. Shulkin, "Rat model for acute myocardial infarction: application to technetium labeled glucoheptonate, tetracycline, and polyphosphate," Journal of Nuclear Medicine, vol. 17, no. 3, pp. 203-207, 1976.

[108] L. H. Michael, M. L. Entman, C. J. Hartley et al., "Myocardial ischemia and reperfusion: a murine model," American Journal of Physiology, vol. 269, no. 6, pp. H2147-H2154, 1995.

[109] J. U. H. Ryu, I. L. K. Kim, S. W. Cho et al., "Implantation of bone marrow mononuclear cells using injectable fibrin matrix enhances neovascularization in infarcted myocardium," Biomaterials, vol. 26, no. 3, pp. 319-326, 2005.

[110] H. A. Rockman, S. P. Wachhorst, L. Mao, and J. Ross, "ANG II receptor blockade prevents ventricular hypertrophy and ANF gene expression with pressure overload in mice," American Journal of Physiology, vol. 266, no. 6, pp. H2468-H2475, 1994.

[111] M. Shimizu, R. Tanaka, T. Fukuyama, R. Aoki, K. Orito, and Y. Yamane, "Cardiac remodeling and angiotensin IIforming enzyme activity of the left ventricle in hamsters with chronic pressure overload induced by ascending aortic stenosis," Journal of Veterinary Medical Science, vol. 68, no. 3, pp. 271-276, 2006.

[112] H. Toko, H. Takahashi, Y. Kayama et al., "Ca2+/calmodulindependent kinase II $\delta$ causes heart failure by accumulation of p53 in dilated cardiomyopathy," Circulation, vol. 122, no. 9, pp. 891-899, 2010.

[113] M. Shiomi, S. Yamada, A. Matsukawa, H. Itabe, and T. Ito, "Invasion of atheromatous plaques into tunica media causes coronary outward remodeling in WHHLMI rabbits," Atherosclerosis, vol. 198, no. 2, pp. 287-293, 2008.

[114] G. E. González, I. M. Seropian, M. L. Krieger et al., "Effect of early versus late AT receptor blockade with losartan on postmyocardial infarction ventricular remodeling in rabbits," American Journal of Physiology, vol. 297, no. 1, pp. H375H386, 2009.

[115] K. Takeuchi, F. X. McGowan Jr., P. Glynn et al., "Glucose transporter upregulation improves ischemic tolerance in hypertrophied failing heart," Circulation, vol. 98, pp. II234II239, 1998.

[116] D. Busseuil, Y. Shi, M. Mecteau et al., "Regression of aortic valve stenosis by ApoA-I mimetic peptide infusions in rabbits," British Journal of Pharmacology, vol. 154, no. 4, pp. 765-773, 2008.

[117] S. J. Lavine, "Effect of changes in contractility on the index of myocardial performance in the dysfunctional left ventricle," Cardiovascular Ultrasound, vol. 4, article 45, 2006.

[118] M. F. M. Van Oosterhout, T. Arts, A. M. M. Muijtjens, R. S. Reneman, and F. W. Prinzen, "Remodeling by ventricular pacing in hypertrophying dog hearts," Cardiovascular Research, vol. 49, no. 4, pp. 771-778, 2001.

[119] M. Koide, M. Hamawaki, T. Narishige et al., "Microtubule depolymerization normalizes in vivo myocardial contractile function in dogs with pressure-overload left ventricular hypertrophy," Circulation, vol. 102, no. 9, pp. 1045-1052, 2000.

[120] Y. Suzuki, J. K. Lyons, A. C. Yeung, and F. Ikeno, "In vivo porcine model of reperfused myocardial infarction: in situ double staining to measure precise infarct area/area at risk," Catheterization and Cardiovascular Interventions, vol. 71, no. 1, pp. 100-107, 2008.

[121] F. G. Spinale, M. L. Coker, C. V. Thomas, J. D. Walker, R. Mukherjee, and L. Hebbar, "Time-dependent changes in matrix metalloproteinase activity and expression during the progression of congestive heart failure: relation to ventricular 
and myocyte function," Circulation Research, vol. 82, no. 4, pp. 482-495, 1998.

[122] M. B. West, G. Rokosh, D. Obal et al., "Cardiac myocytespecific expression of inducible nitric oxide synthase protects against ischemia/reperfusion injury by preventing mitochondrial permeability transition," Circulation, vol. 118, no. 19, pp. 1970-1978, 2008.

[123] W. G. Kim, Y. C. Shin, S. W. Hwang, C. Lee, and C. Y. $\mathrm{Na}$, "Comparison of myocardial infarction with sequential ligation of the left anterior descending artery and its diagonal branch in dogs and sheep," International Journal of Artificial Organs, vol. 26, no. 4, pp. 351-357, 2003.

[124] M. Shiomi, T. Ito, S. Yamada, S. Kawashima, and J. Fan, "Development of an animal model for spontaneous myocardial infarction (WHHLMI rabbit)," Arteriosclerosis, Thrombosis, and Vascular Biology, vol. 23, no. 7, pp. 12391244, 2003.

[125] Y. Kuge, N. Takai, Y. Ogawa et al., "Imaging with radiolabelled anti-membrane type 1 matrix metalloproteinase (MT1-MMP) antibody: potentials for characterizing atherosclerotic plaques," European Journal of Nuclear Medicine and Molecular Imaging, vol. 37, pp. 2093-2104, 2010.

[126] H. Schunkert, V. J. Dzau, S. S. Tang, A. T. Hirsch, C. S. Apstein, and B. H. Lorell, "Increased rat cardiac angiotensin converting enzyme activity and mRNA expression in pressure overload left ventricular hypertrophy. Effects on coronary resistance, contractility, and relaxation," Journal of Clinical Investigation, vol. 86, no. 6, pp. 1913-1920, 1990.

[127] D. M. Eble, J. D. Walker, A. M. Samarel, and F. G. Spinale, "Myosin heavy chain synthesis during the progression of chronic tachycardia induced heart failure in rabbits," Basic Research in Cardiology, vol. 93, no. 1, pp. 50-55, 1998. 


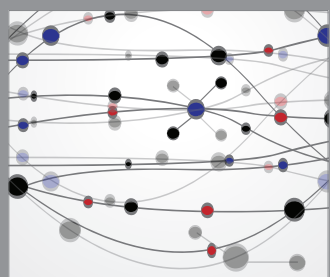

The Scientific World Journal
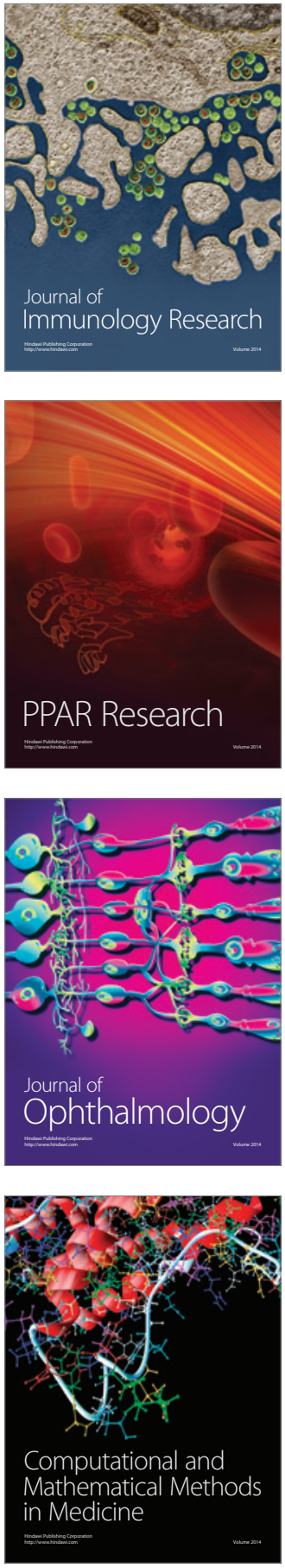

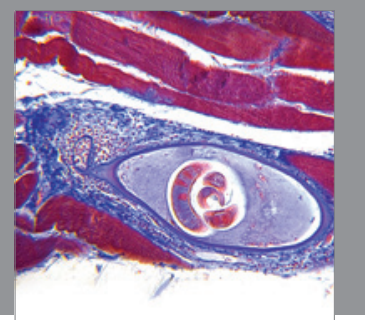

Gastroenterology

Research and Practice
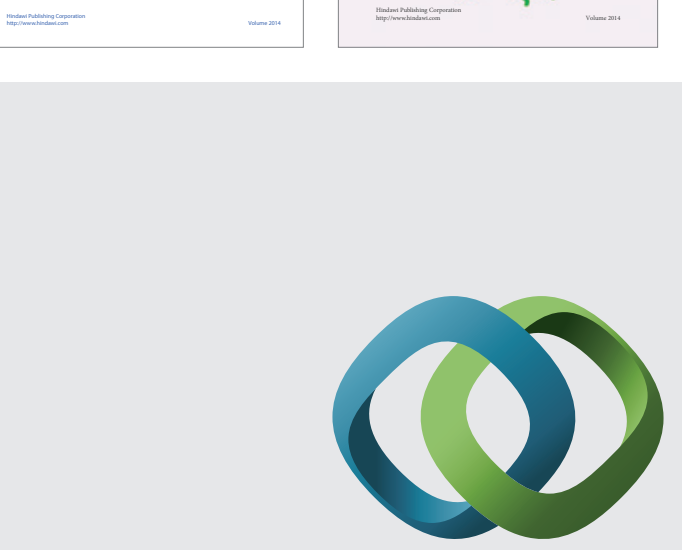

\section{Hindawi}

Submit your manuscripts at

http://www.hindawi.com


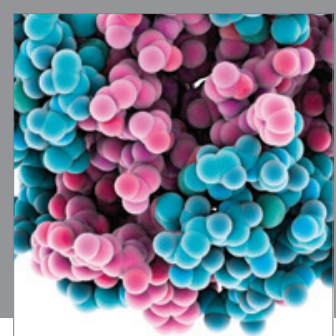

Journal of
Diabetes Research

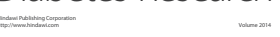

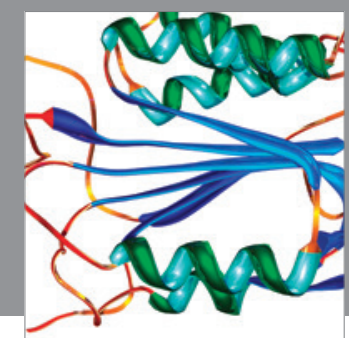

Disease Markers
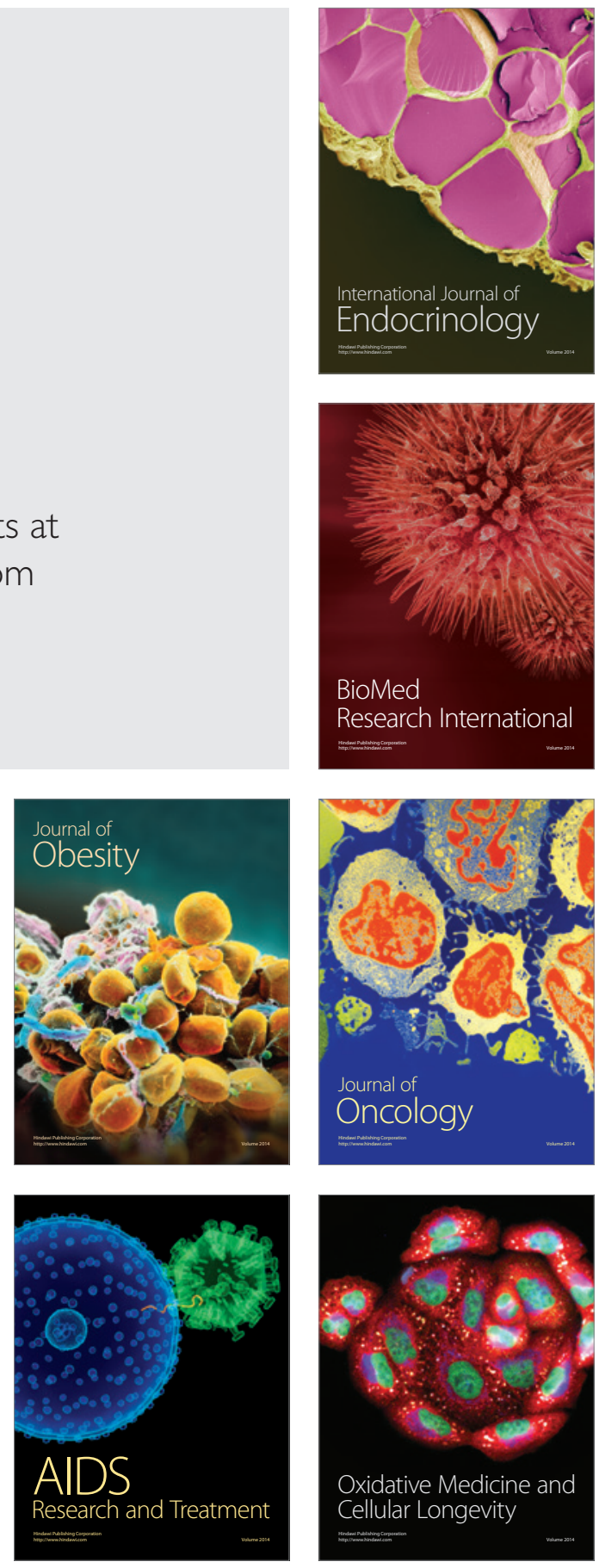